\title{
A VIVÊNCIA DE ALUNOS DE GRADUAÇÃO EM ENFERMAGEM NA ASSISTÊNCIA À SAÚDE DA MULHER EM UMA COMUNIDADE DE BAIXA RENDA - UMA ABORDAGEM FENOMENOLÓGICA.
}

\section{THE BACKGROUND GOT ON ASSISTANCE TO WOMAN HEALTH IN A LOW INCOME COMMUNITY BY UNDERGRADUATE STUDENTS OF NURSING. A PHENOMENOLOGICAL APPROACH}

\author{
Miriam Aparecida Barbosa Merighi * \\ Isabel Cristina Bonadio *
}

MERIGHI, M.A.B.; BONADIO, I.C. A vivência de alunos de graduaçăo em enfermagem na assistência à saúde da mulher em uma comunidade de baixa renda - uma abordagem fenomenologica. Rev.Esc.Enf.USP, v.32, n.2, p.109.16, ago. 1998. \begin{abstract}
Wrstoro
Neste estudo nossa trajetória dirigiu-se para a compreensão da experiência vivida pelos alunos do Curso de Graduação em Enfermagem da EEUSP, na assistência à mulher em uma comunidade de baixa renda da cidade de São Paulo. Obtivemos descrições dos alunos e os dados foram analisados seguindo os passos da fenomenologia. Identificamos cinco temas: experiência gratificante, estimulante e valiosa; experiência de vida, de crescimento pessoal e de quebra de preconceito; atividade que permite conhecer o outro lado da assistência; atividade prática que possibilita sedimentação do conhecimento adquirido teoricamente; experiência importante e necessária. A experiência vivenciada pelos alunos mostrou-se satisfatória favorecendo o processo de ensino-aprendizagem.
\end{abstract}

UNITERMOS: Ensino de enfermagem. Fenomenologia.

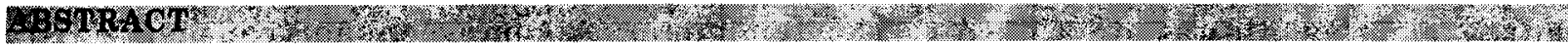

Our trajectory in this study has addressed to the comprehension of experience which undergraduate students in the Nursing School of USP. This work has been developed in a low incomme community of São Paulo city. We've got descriptions of the students and the data were discussed following the steps of phenomenological assay. We've identified five themes: rewarding experience, stimulant and necessary; experience of life, personal growth and disrupting with prejudice; activity which permits to know the other side of assistance; important and valuable experience; practice activity which makes possible the acquired know!edge sedimentation theoretically. The graduation students experience was satisfactory and it was favorable to the teaching-learning process.

UNITERMS : Education in nursing. Phenomenology.

\section{INTRODUÇÃO}

Nos, enfermeiras obstetras, docentes da Disciplina Enfermagem Obstétrica, do Departamento de Enfermagem Materno-Infantil e Psiquiátrica da Escola de Enfermagem da Universidade de São Paulo (ENP-EEUSP), desde abril de 1994, desenvolvemos um Programa de Atenção à Saúde da Mulher e Perinatal, em uma comunidade de baixa renda localizada no bairro do Jaguaré, na zona oeste da cidade de São Paulo. Esse
Programa tem caráter de extensão de serviços à comunidade, de ensino e de pesquisa. As atividades desenvolvidas visam a melhora das condições de vida da população atuando, principalmente, na área de atenção primária de saúde, almejando a diminuição da morbi-mortalidade materna e perinatal, através da identificação de causas preveníveis e controláveis durante os periodos pré e pós-natal.

\footnotetext{
* Enfermeira Obstétrica. Professor Doutor do Departamento de Enfermagem Materno-Infantil e Psiquiátrica da EEUSP
} 
Para o desenvolvimento do Programa contamos com a colaboração da Unidade Básica de Saúde da Vila Nova Jaguaré e do Hospital Universitário da USP, pelo fato da Comunidade pertencer à região de abrangência dessas Instituições. A Unidade Básica presta atendimento médico para os casos necessários e fornece material de consumo, enquanto o Hospital Universitário garante $o$ atendimento ao parto, agenda a consulta de retorno do binômio mãe-filho para atendimento na Comunidade, bem como realiza alguns exames subsidiários.

As atividades de assistência desenvolvidas junto às mulheres residentes nessa comunidade envolvem a consulta de pré-natal às gestantes de baixo risco obstétrico; a consulta de enfermagem ao binômio mãe-recém-nascido; a visita domiciliária às puérperas que apresentam problemas médico-sociais detectados na consulta de enfermagem e/ou às puérperas que tiveram recém-nascidos prematuros ou com alguma intercorrência. É realizada, também, a coleta de material para citologia oncológica para a detecção precoce do câncer ginecológico.

Quanto ao ensino, nosso objetivo é oferecer ao aluno de graduação e de pós-graduação em Enfermagem Obstétrica a oportunidade de prestar assistência à mulher, no seu real contexto social, proporcionando-lhe outra perspectiva da assistência, qual seja, a extra-hospitalar.

Desde a implantação do Programa, as atividades assistenciais vinham sendo desenvolvidas pelas docentes e pelas alunas do Curso de Especialização em Enfermagem Obstétrica, sob a supervisão da docente. No primeiro semestre do período letivo de 1995 , os alunos de graduação em Enfermagem da EEUSP, cursando a disciplina Enfermagem na Saúde da Mulher vivenciaram uma parte do ensino térico-prático da disciplina, participando no desenvolvimento de atividades deste Programa, na referida comunidade.

Como esta seria a nossa primeira experiência no desenvolvimento de ensino teórico-prático para alunos de graduação em Enfermagem, prestando assistência no âmbito comunitário, após anos de experiência apenas intra-hospitalar, trouxe-nos muitas expectativas e inquietações.

Durante o desenvolvimento da disciplina acima citada, uma questão já se fez presente como norteadora do fenomeno que gostaríamos de identificar, na experiência do aluno: como é sua vivência do ensino teórico-prático na assistência de Enfermagem à mulher em uma comunidade de baixa renda.

\section{TRAJETÓRIA METODOLÓGICA}

\section{Considerações sobre a escolha da metodologia}

Com a finalidade de melhor conhecer e compreender a experiência vivenciada por alunos de graduação em Enfermagem na assistência em uma comunidade de baixa renda, interrogamos, neste estudo, como foi para eles prestar assistência de Enfermagem nesta comunidade. Por meio dos discursos dos próprios alunos é que pretendemos que este fenômeno se mostre.

Para obtermos uma compreensão mais global de uma experiência vivida pela pessoa, a partir de sua própria perspectiva, consideramos que uma pesquisa qualitativa se apresentava como o caminho mais coerente aos nossos propósitos, decidindo, assim, trabalhar na linha fenomenologica.

CRITELLI (1984) diz que fenomenologia "é uma postura, uma proposta, um método, uma atitude reflexiva que questiona verdades e fins". Assim nossa opção pela fenomenologia surgiu da afinidade entre a sua epistemologia, o fenômeno que pretendemos estudar e a nossa postura enquanto pesquisadora.

Com a intenção de compreender o vivido é que desenvolvemos este trabalho pois, para que o fenômeno se mostre não basta vivê-lo, aquilo que conhecemos não é suficiente para que apreendamos o fenômeno. A compreensão transcende esta perspectiva através do ver e do sentir do outro (MERIGHI, 1993).

A fenomenologia pensada por Husserl é uma volta ao mundo vivido, ao mundo da experiência que, para ele é o ponto de partida de todas as ciências. A fenomenologia propõe a descrição do fenômeno e não explicação ou busca de relações causais empregando, necessariamente, uma forma de reflexão que deve incluir a possibilidade de olhar as coisas como elas se manifestam (CAPALBO, 1994). Nesse sentido, a fenomenologia não se propõe a fazer generalizações, princípios e leis. A preocupação está em mostrar e não demonstrar.

O método fenomenológico é intuitivo e descritivo. O objetivo do método é descrever a estrutura total da experiência vivida, incluindo o significado que estas experiências representam para os indivíduos que delas participam. A fenomenologia não ocupa-se da explicação, mas sim da compreensão do fenômeno, por isso vem ao encontro do propósito deste estudo.

O método fenomenológico não se limita a uma descrição passiva das experiências vividas. É, simultaneamente, tarefa de interpretação que 
consiste em revelar (por a descoberto), os sentimentos menos aparentes, os que o fenômeno tem de mais fundamental, ou seja a sua essência (MANSINI, 1991).

Nessa modalidade de estudo, o pesquisador recusa pressupostos ou pré-conceitos sobre a natureza do fenômeno investigado. Em lugar disso, procura solicitar que os sujeitos descrevam em sua própria linguagem, as experiências que estão tendo em uma dada situação de vida. Espera-se que estes sejam capazes de descrever o que estão experiençiando de modo mais adequado do que o pesquisador pode vir a fazer e, ainda, que sejam capazes de experienciar o fenômeno de maneira não imaginada por ele, pesquisador (MARTINS et al., 1990).

MERLEAU - PONTY (1971) discorrendo sobre a fenomenologia destaca que, mesmo tendo passado meio século, desde o início dos trabalhos nessa abordagem, questões permanecem não resolvidas porque a fenomenologia é um constante recomeçar. Assim, é reconhecida como movimento vivido que busca a essência dos fenômenos.

A fenomenologia terá compreensões diversas em Hegel, Husserl, Heidgger e Merleau-Ponty, todos vão em busca da essência, no entanto Merleau-Ponty é enfático em afirmar que se a fenomenologia é considerada o estudo das essências, é também uma filosofia que coloca a essência na existência.

Assim, fenomenologia para Merlau-Ponty "éo estudo das essências, é uma filosofia sem a qual não se pode compreender o homem e o mundo senão a partir de sua facticidade; é uma filosofia transcedental que coloca entre parêntese, para compreende-las, as afirmações da atitude natural, é também a filosofia para a qual o mundo é sempre "dejá-lá" antes da reflexão. É, além disso, a tentativa de uma descrição direta de nossa experiência tal como é, sem levar em conta a sua gênese psicológica e as implicações causais do cientista..." (VON ZUBEN, 1984).

Nesse contexto, Merleau-Ponty toma como ponto de partida o fenômeno do comportamento e nele a percepção é o primeiro contato com o mundo. Nesta factilidade, escolhe o corpo como o sujeito da percepção do sentido, do significado. Apresenta a concepção do corpo como corpo-sujeito, superando com isto o conceito cartesiano, isto é, a separação entre o corpo e o espírito.

Assim, Merleau-Ponty refere-se à percepção como uma forma da consciência; o corpo proporciona o acesso ao mundo e, a percepção é nosso acesso à experiência no mundo, antes da reflexão.
Acreditamos que o fenômeno a ser investigado aproxima-se da fenomenologia existencial e com essa abordagem procuramos compreender os significados atribuídos pelos alunos de graduação em enfermagem e através de suas descrições chegar à essência " desse fenômeno.

\section{MOMENTOS DA TRAJETÓRIA}

A trajetória fenomenologica consiste de três momentos: a descrição, a redução e a compreensão.

A descrição fenomenologica, primeiro momento da trajetória na pesquisa, ao ser proposta por Merleau-Ponty, constitui-se das percepções da pessoa que definem os limites expressos da troca com o mundo. É através do discurso que se chega às condições essenciais do fenômeno.

A medida em que o pesquisador vai se familiarizando com as descrições, através de repetidas leituras, vão surgindo unidades de significados, que são identificadas pelo pesquisador, conforme sua ótica, de tal forma a sistematizar o que é vivido pelo sujeito que está descrevendo o fenômeno. Quando o pesquisador chega a uma visão do todo, sente-se apto para iniciar a redução do fenômeno.

A redução, segundo momento da trajetória, tem como objetivo determinar, selecionar quais as partes da descrição que são consideradas essenciais e quais não são.

A redução fenomenológica, é a resolução não de suprimir, mas de colocar em suspenso e, como fora de ação, todas as afirmações espontâneas nas quais vivo, não para negá-las, e sim para compreendê-las.

Neste sentido, MERLEAU-PONTY (1973) refere: "Quando opero a redução fenomenológica, não me reporto ao mundo exterior, não substituo a percepção interior à exterior; tento fazer aparecer e explicitar em mim essa fonte pura de todas as significações que em torno de mim constituem o mundo, e que constitui meu eu empírico".

Deseja-se encontrar, exatamente, a parte da experiência que é verdadeiramente parte da consciência do sujeito diferenciando-a daquela que é simplesmente suposta.

A compreensão fenomenológica, o terceiro momento, surge sempre em conjunto com a interpretação. Este momento é uma tentativa de especificar o significado, que é essencial na descrição e na redução, como uma forma de investigação da experiência.

\footnotetext{
- essencia - característica que faz com que algo ou alguém seja aquilo que é, é a verdade.
} 
O pesquisador assume o resultado da redução como um conjunto de asserções significativas para ele, pesquisador, mas que apontam para a experiência do sujeito. Em seguida, o pesquisador transforma as expressões cotidianas do discurso do sujeito em expressões próprias que sustentam o que está buscando. Esta transformação fundamenta-se na reflexão.

Quando as descrições convergirem, isto é, houver repetições nos discursos, quando o interrogar estiver desocultado, pode-se dizer que o fenômeno já se mostrou e chegou-se a apreensão dos significados essenciais, o discurso foi esclarecedor.

\section{CONSTITUIÇÃO DOS DADOS}

Ao término da disciplina Enfermagem na Saúde da Mulher solicitamos aos alunos que descrevessem a experiência vivenciada durante o ensino teórico-prático desenvolvido na comunidade.

Como forma de interrogar e revelar o fenômeno, as descrições foram norteadas por meio de uma pergunta orientadora: Para você, como foi desenvolver atividades nesta comunidade?

Entregamos aos alunos, no dia programado para a avaliação final da disciplina, um impresso contendo um preâmbulo com a finalidade de deixar clara nossa intenção quanto à questão orientadora (ANEXO). Declaramos nossa intenção em realizar uma pesquisa e que para tal, seria muito importante a participação e colaboração de todos. Dissemos também, que não era necessário identificarem-se.

\section{NÚMERO DE SUJEITOS}

O número de alunos considerados sujeitos da pesquisa foi definido pela análise das proprias descrições. Dessa forma, obtivemos discurso de 13 alunos, trabalhamos com todos os discursos obtidos, ao se constatar que seriam suficientes para responder a interrogação proposta: como foi, para o aluno de graduação, prestar assistência de enfermagem à mulher em uma comunidade de baixa renda e de que forma essa vivência contribui na formação profissional do enfermeiro.

\section{O MOMENTO DA ANÁLISE}

Para efetuar a análise dos dados, numeramos os discursos de I a XIII e realizamos leituras completas, com atenção e critério, porém não interpretativa e nem com o objetivo de proceder a análise enquanto texto, mas sim com a finalidade de apreender o sentido global do discurso.

Após extrairmos deles as unidades de significado, isto $e$, os aspectos essenciais do fenômeno que mostravam-se significativos para nós, enquanto pesquisadoras, iniciamos a análise dos dados através da redução fenomenologica. Foi desconsiderado para efeito da análise, tudo o que não dizia respeito ao fenômeno. Mantivemos somente as proposições significativas.

Destacamos as unidades de significado, e numeramos uma a uma (seqüência numérica em algarismo arábico). Com isso, obtivemos uma visão global do discurso e do local onde se encontravam os significados. A seguir, as unidades de significados foram reescritas na busca da clareza do discurso, procurando expressar seu pensamento articulado (redução). Estes procedimentos foram feitos para cada um dos discursos dos sujeitos.

Em seguida, buscamos as convergências das unidades de significado dentro de cada discurso, ou seja, reunimos as unidades que se referiam ao mesmo assunto ou que possuíam o mesmo conteúdo. Estas foram agrupadas com a finalidade de organizar as articulações do discurso, formando núcleos de pensamentos, que foram sintetizados e tematizados conforme várias perspectivas que emergiram das experiências dos alunos.

A tematização surgiu do agrupamento das unidades de significado, evidenciando-se, assim, cinco diferentes temas: como uma experiência gratificante, estimulante e valiosa; como uma experiência de vida, de crescimento pessoal e de quebra de preconceito; como uma atividade prática que possibilita sedimentação do conhecimento adquirido teoricamente; como uma atividade que permite conhecer o outro lado da assistência; como uma experiência importante e necessária.

\section{CONSTRUINDO OS RESULTADOS}

A análise compreensiva dos discursos revelounos que, aos olhos dos alunos, ter vivenciado uma experiência assistencial de enfermagem na saúde da mulher, na comunidade mostrou-se como:

\section{UMA EXPERIÊNCIA GRATIFICANTE, ESTIMULANTE E VALIOSA}

- "Além de poder desenvolver experiência nessa área, é muito gratificante, pode-se ter uma visão geral de como é organizar todo um trabalho perante a comunidade". 
- "Para mim, foi muito gratificante poder participar desta atividade na comunidade; ...".

- "...desenvolver atividades na comunidade foi algo estimulante".

- "E muito bom descobrir que mesmo quase sem saber nada ainda, aquelas pessoas nos olham e esperam de nós soluções, ajuda, orientações, ou seja, o pouco que sabemos já começa a servir para ajudar pessoas e isso é uma sensação maravilhosa".

- "Foi uma experiência nova e rica onde pude perceber novas nuances da sociedade em que vivemos".

\section{UMA EXPERIÊNCIA DE VIDA, DE CRESCIMENTO PESSOAL E DE QUEBRA DE PRECONCEITO}

- "Para mim não foi só um estágio, foi uma experiência de vida, lá eu pude ver coisas que são muito valiosas, saber como as pessoas pensam, vivem; saber dos seus sentimentos, do seu cotidiano, seus valores e assim reavaliar os meus valores".

- "A experiência (...) foi extremamente proveitosa. Representou mais uma "lição de vida" do que "estágio curricular" embora tenha consolidado muito bem a teoria dada em sala de aula".

- "Aprendi a valorizar mais a vida e as pessoas".

- "Foi uma grande experiência. Entrei num mundo que não conhecia e que me fez repensar muitos momentos de minha vida. Percebi que os meus problemas são muito pequenos quando comparados aos dos moradores da comunidade".

- "Deparar-me com uma realidade tão difícil, foi muito complicado (...) contudo, cresci pessoalmente e profissionalmente. Sei que ainda tenho muitas barreiras a ultrapassar, mas sei que esta eu consegui enfrentar, o que fez com que eu expandisse a minha visão de mundo".

- "(..) Além disso me fez crescer mais como pessoa, pois me livrei de um preconceito que eu nem sabia que tinha, que é a questão de como eu enxergava uma favela, o que achava da favela".

- "Meu maior problema, o mêdo, foi adentrar num local tão cheio de mitos e fantasmas. Ouvi relato de "pessoas mal encaradas te examinando", "cheiro de esgoto insuportável". Na verdade não foi nada disso (...), no entanto, o que pude notar foi receptividade e disposição das pessoas em escutarem o que tínhamos a dizer".
- "Senti medo a princípio de estar indo para o meio de uma favela, mas graças a esta experiência, hoje isto não acontece mais".

\section{UMA ATIVIDADE QUE PERMITE CONHE- CER O OUTRO LADO DA ASSISTÊNCIA}

- "Conheci um lado da enfermagem que eu não havia tido contato ainda, e isso foi super legal".

- “Foi muito bom mesmo. Me fez ver um outro lado da saúde, foi bem diferente. Acho que o enfermeiro consegue desenvolver bem o papel de educador na comunidade".

- "Entendi que apesar de poucos recursos é possível prestar uma assistência de saúde boa e que espera para atender aquilo que a comunidade traz, ao invés de seguir sempre com o mesmo roteiro de assistência".

- "Na comunidade percebi que as mulheres se sentem mais a vontade, parecem estar em suas casas. Isso facilita a assistência, pois elas contam sobre seus problemas sem medo, e o que também favorece a interação enfermagem-paciente".

- "Me senti mais segura na comunidade (não sei o por quê!). Fica bem claro para nós se uma determinada mulher tem condições ou não de estar seguindo as orientações prestadas a ela na comunidade".

- "O contato com as clientes foi muito interessante. Esse contato fora da instituição hospitalar, forneceu uma visão das clientes mais próximas da realidade".

- "É através do conhecimento da realidade em que vivem as mulheres e seus bebês (família) na comunidade é perceptível que se repense essa assistência de enfermagem prestada em campo hospitalar, pois muitas vezes esta se encontra totalmente longe dos parâmetros de vida desta população".

- "Foi interessante fazer a visita domiciliária para entender um pouco mais a vida dessas pessoas e o porquê da não procura da assistência em determinados casos".

- "As visitas domiciliares permite que o aluno, ou pelo menos me permitiu entender melhor o conceito de saúde onde envolve o lado biológico, psicológico e social do indivíduo". 


\section{UMA ATIVIDADE PRÁTICA QUE POSSIBI- LITA SEDIMENTAÇÃO DO CONHECIMEN- TO ADQUIRIDO TEORICAMENTE}

- "Para mim foi importante também para que a prática fosse correlacionada a teoria dada em sala de aula".

- "Foi possível sedimentar os conhecimentos adquiridos nas aulas teóricas".

- "Para mim foi de grande valor desenvolver atividades nesta comunidade, pois pude por em prática o que havia aprendido nos meus estudos e também pude conhecer a população da comunidade e suas crenças, modo de vida".

- "É um campo muito rico em adquirir conhecimento para melhor assistência de enfermagem à mulher, conhecimento este e experiência que não encontramos em livros, mas só com a convivência e acompanhamento das professoras é que podemos adquirir uma visão mais clínica da realidade que estamos nos inserindo".

\section{UMA EXPERIÊNCIA IMPORTANTE E NECESSÁRIA}

- "Este estágio é muito importante para que o aluno tenha uma visão mais ampla da realidade do indivíduo que estamos cuidando".

- “(...). Pude avaliar a importância de se conhecer a situação econômica e psicológica da paciente para traçar objetivos visando a qualidade da assistência".

- "Desenvolver as atividades na comunidade foi uma experiência muito importante. (...) percebi que as atividades realizadas na Comunidade foram muito importantes para o meu aprendizado, pois foram oportunidades de entrar em contato com uma assistência de enfermagem diferente das realizadas na Instituição hospitalar".

- "Eu espero que todos os alunos que estão se formando, que estão cursando enfermagem passem por esta experiência, que saia um pouco do âmbito hospitalar e vá vivenciar atividades desenvolvidas na comunidade".

- "Desenvolver as atividades na comunidade foi de grande importância, pois através deste estágio pude ver a diferença existente na assistência de enfermagem no hospital e neste campo".

- "Um ponto importante nos estágios da comunidade, foi a liberdade que tivemos em atuar."

\section{A COMPREENSÃO DO FENÔMENO}

A análise dos temas obtidos indicaram que a essência do fenômeno estudado foi revelada, sendo assim compreendida a interrogação.

Vários sujeitos comentam que a atividade desenvolvida na comunidade possibilita 0 conhecimento do "outro lado" da assistência, mostrando a diferença entre a assistência hospitalar e a comunitária permitindo, assim, a prestação de uma assistência diferenciada, maior liberdade de atuação e conscientização sobre a necessidade de repensar a assistência hospitalar. Um aluno menciona que a qualidade da assistência depende da satisfação da clientela e não da quantidade de recursos. Destaca-se em várias unidades de significado, que as atividades na comunidade possibilitam a sedimentação dos conhecimentos adquiridos nas aulas teóricas, permitindo correlacionar a teoria com a prática. A conscientização da realidade social da clientela assistida possibilita, além da aquisição e sedimentação de conhecimentos impossiveis de serem adquiridos em livros, um crescimento pessoal, uma lição de vida, ou seja, torna-se mais do que simplesmente um estágio curricular

Alguns alunos referem-se à ruptura de "preconceito" e à perda do "medo", existentes antes de iniciarem as atividades na comunidade de baixa renda, por tratar-se de local repleto de "mitos $e$ fantasmas".

Os alunos mencionam as visitas domiciliares, afirmando que estas facilitam o entendimento do conceito de saúde, pois abrangem o âmbito bio-psicosocial. Para eles, essa atividade mostrou-se como uma experiência ímpar para conscientizarem-se de que 0 atendimento à saúde de forma contextualizada não é tarefa fácil, sobretudo em se tratando de trabalho com personagens que vivem sob condição crônica de pobreza e marginalidade.

Em uma unidade de significado ficou evidenciado a necessidade do sistema de referência e contra-referência, para uma assistência efetiva quando resgatamos a fala do sujeito: “... ficou evidente a importância da assistência de enfermagem e da necessidade de integração com outros serviços de saúde para uma assistência efetiva e para evitar complicações no ciclo grávido-puerperal ...". Esta unidade de significado é uma idiossincrasia, pois representa a maneira de sentir o fenômeno de forma individualizada, ou seja, de apenas um sujeito. Isto não significa que esses aspectos não possam pertencer à consciência de outros alunos; um discurso não reflete a totalidade das experiências vividas mas algo que tenha maior significação no 
conjunto das ações desenvolvidas pelo sujeito entrevistado. A consideração das individualidades no conhecimento estrutural do fenômeno encontra, portanto, justificativa (MERIGHI, 1993).

Nas descrições dos alunos surgiram unidades de significado divergentes das demais, como podemos resgatar na seguinte fala: "como o campo é único da enfermagem, há a possibilidade de prestar assistência de acordo com a visão que adquirimos nas aulas teóricas com as docentes e não adaptada à filosofia de outros profissionais que às vezes prejudicam a nossa atuação", apontando para um aspecto não positivo do ensino teórico-prático da disciplina pelo campo ser de atuação exclusiva de enfermeiros. No entanto, o aluno vivenciou este fato de forma positiva, alertando-nos sobre a necessidade de proporcionar ao graduando a oportunidade de atuação junto a outros profissionais de saúde além do enfermeiro ou enfermeiro obstetra. Dessa forma, estaremos proporcionando ao aluno experiência de aprendizado com o trabalho multidisciplinar, conscientizando-o da importância da inserção do enfermeiro na equipe de saúde.

Pela análise das descrições fica evidente que os alunos consideram importante e necessário que todos vivenciem a assistência de enfermagem em comunidade, além da hospitalar, e, que esta experiência foi gratificante, estimulante, muito rica e valiosa. O fato dos alunos terem vivenciado o ensino teórico-prático da disciplina Enfermagem na Saúde da Mulher desenvolvido em comunidade de baixa renda de modo positivo, de alguma forma contribuiu na sua formação de enfermeiro.

\section{REFLETINDO SOBRE O FENÔMENO}

Este estudo, sobretudo, permitiu-nos a possibilidade de refletir sobre "o nosso modo de ser docente". A inquietação inicial quanto ao desenvolvimento do ensino teórico-prático no âmbito comunitário não mais se faz presente, uma vez que a experiência do aluno mostrou-se satisfatória não apenas para a aquisição de conhecimento mas, também, como lição de vida e de crescimento pessoal.

Resgatamos, através da análise dos temas, que o processo de ensino-aprendizagem vivenciado na comunidade favorece a capacitação do aluno em relacionamento interpessoal, pela oportunidade de interação aluno-cliente no seu próprio contexto social. O contexto no qual ocorre a experiência do aluno retrata as condições sócio-econômicas e culturais em que vive a maioria da população brasileira, evidencia a inoperância do sistema de saúde vigente, possibilitando a formação do enfermeiro com capacidade crítica e criativa, com possibilidade de atuação compromissada e adequada às condições de sua clientela.

As convergências entre as unidades de significados mostram a importância dos brgãos formadores oferecerem aos graduandos, a oportunidade de atuação no âmbito extra-hospitalar, pela positividade das experiências vivenciadas pelos alunos. A experiência do ensino teórico-prático assim vivenciada pelos alunos contribui para a visão holística do homem enquanto ser inserido em uma dada sociedade histórica e culturalmente situada.

Olhamos com satisfação para o Programa de Atenção à Saúde da Mulher e Perinatal desenvolvido por nós, pela contribuição positiva para o ensino de graduação em enfermagem e, também pela produção de conhecimento sobre saúde materna e perinatal, o que tem repercutido para a melhora das condições de saúde de parte da população de uma comunidade de baixa renda da cidade de São Paulo.

A abordagem fenomenológica adotada neste estudo foi pertinente ao que nos propusemos a investigar, possibilitando a apreensão do fenômeno. Nessa apreensão está contida um des-velamento, uma iluminação daquilo que se mostra a nós docentes, enquanto fenômeno investigado: vivenciar o ensino teórico-prático de enfermagem em uma comunidade de baixa renda.

\section{REFERÊNCIAS BIBLIOGRÁFICAS}

CAPALBO, C. Abordando a enfermagem a partir da fenomenologia. Rev. Enf. UERJ, v. 2, n. 1, p. 70-6, 1994.

CRITELLI, D.M. Ontologia do cotidiano o resgate do ser: poética heidèggeriana. In: MARTINS, J.; DICHTCHEKENIAN, M.F.S.F.B. Temas fundamentais da fenomenologia. Sao Paulo, Moraes, 1984, p. 17-25.

MANSINI, E. Enfoque fenomenológico da pesquisa em educação In: FAZENDA, I.C.A. Metodologia da pesquisa educacional. 2.ed. São Paulo, Cortez, 1991. p.59-67.

MARTINS, J. et al. A fenomenologia como alternativa metodológica para pesquisa. Cad.Soc.Est.Qual., v. 1, n. 1, p. $33-47,1990$.

MERIGHI, M.A.B. A docência de enfermagem em uma Universidade Pública - um enfoque fenomenologico. Săo Paulo, 1993. 217 p. Tese (Doutorado) - Escola de Enfermagem, Universidade de São Paulo.

MERLEAU-PONTY, M. Fenomenologia da percepção. Rio de Janeiro, Freitas Bastos, 1971.

MERLEAU.PONTY, M. Ciência do homem e fenomenologia . Såo Paulo, Saraiva, 1973.

VON ZUBEN, N.A. Fenomenologia e existência: uma leitura de Merleau-Pouty. In: MARTINS, M.; DICHTCHEKENIAN, M.F.S.F.B. Temas fundamentais de fenomenologia. São Paulo, Moraes, 1984. p. 55-68. 


\title{
ANEXO
}

Caro aluno,

Realizarei um estudo qualitativo, cujo objetivo é conhecer a opinião dos alunos șobre a experiência vivenciada na Comunidade Nossa Senhora Aparecida da Vila Nova Jaguaré.

Para tanto, gostaria que você discorresse sobre a questão:

- Para você, como foi desenvolver atividades nessa Comunidade?

\author{
Atenciosamente,
}

